\title{
Incidence of sporting injury in New Zealand youths aged $6-15$ years
}

\author{
R G Pringle, P McNair, S Stanley
}

\begin{abstract}
Objective-To document the incidence of injury in 6-15 year olds playing rugby union, rugby league, and netball, and to identify the common mechanisms, sites, severity, and time of injury.

Methods-Cross sectional data were collected by trained observers who watched 258 games of rugby union, netball, and rugby league over a four week period. The condition of the injured participants was monitored until recovery.

Results-In total, 5174 players were observed and an injury rate of 18 per 1000 player hours was calculated. Of all observed injuries, $29 \%$ required some form of medical treatment. A significant difference $(p<0.05)$ in the distribution of injury over the four quarters of the games was recorded, most occurring in the first three quarters. In total, $81 \%$ of the injuries were classified as contact injuries, and these mainly occurred through direct contact with the opposition. Of all observed injuries, $27 \%$ were recurrent.

Conclusions-The incidence of injury in rugby union, netball, and rugby league is low for children aged between 6 and 15 years relative to adult rates.

(Br F Sports Med 1998;32:49-52)
\end{abstract}

Keywords: injury incidence; youth sport; rugby union; netball; rugby league

Extensive participation in sport by children and young adolescents is a comparatively new phenomenon in New Zealand. ${ }^{1}$ Currently it is not uncommon for children to have their first exposure to competitive sport at the ages of 4 or 5. This trend of participation at young ages has generated research related to the social, psychological, and physiological effects on the participants. $^{23}$ A major focus of this type of research is determining if benefits outweigh any potential negative consequences. Many studies have investigated injury occurrence in adult sport, but concern has been expressed on the paucity of research into children's sports injuries..$^{4-6}$ Although many of the factors that influence adult injury patterns are applicable to children's injuries, there is a need for epidemiological studies to be focused on young athletes. ${ }^{7}$ A physiological example indicating the difference between adult and youth participants relates to the processes of growth and maturation. The immature musculoskeletal system may be more susceptible to injury than that of the adult, and epiphyseal injury has the potential to disrupt growth. ${ }^{4}$
Research that has focused on children's sports injuries has tended to collect results through the use of medical databases, analysis of insurance claims, or retrospective questionnaires. These methods have the advantage of being able to sample large populations, but can suffer some deficiencies with respect to obtaining accurate or detailed information. Retrospective study designs can be flawed through incorrect recall, and studies utilising medical records or insurance claims are based on biased evidence, as not all injuries are recorded. ${ }^{7}$ Such knowledge may be vital to devising strategies for decreasing the rate of injury.

The lack of specific information pertaining to injury rates in children and youths provided the impetus to develop a study in this area, its purpose being to document the incidence of injury in 6-15 year olds playing rugby union, rugby league, and netball. These three team sports were selected because of their high participation rates $^{8-10}$ and dynamic nature. In addition, the adult injury rates within these sports are among the highest in New Zealand and the cost is considerable. ${ }^{11}{ }^{12}$ This study also sought to identify the common mechanisms, sites, and severity of injury in children playing these sports.

\section{Methods}

Cross sectional data were collected by trained observers who watched 258 games ( 516 teams) of rugby union, rugby league, and netball. The games were observed at 15 venues throughout Auckland city and its surrounding suburbs. These venues were the primary areas where children's competitive sport is played by the three sporting codes. The games were all formally organised and part of ongoing competitions being played over a season. They were observed over a four week period by 20 data collectors. The observers were physiotherapy or sport science students with suitable training in anatomy and sports medicine. The observers were provided with detailed instruction on ethical and procedural facets of data collection. To enhance reliability, data collectors presented their results individually to an experienced physiotherapist and the primary author to ensure that correct procedures had been followed.

Observers completed an incident sheet each time an injury occurred that impaired a player's performance. In order to collect further information, each player involved in an injury incident was interviewed after the game in conjunction with the coach or parent/ guardian. For each of the observed incidents, a trained telephone interviewer (a registered 


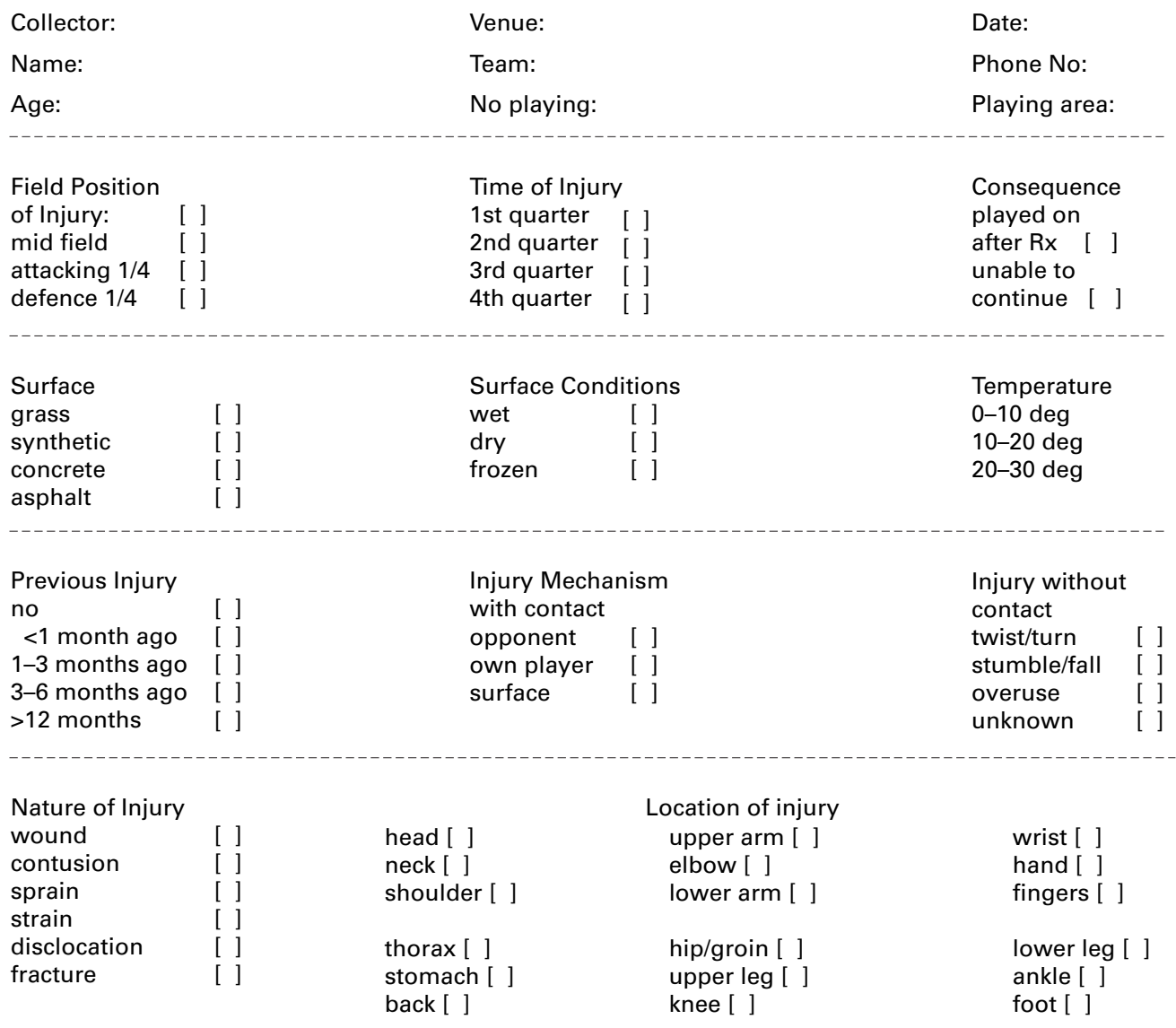

Structure involved

bone [ ] muscle [ ] tendon [ ] ligament [ ]

Figure 1 Sports injury incident form.

physiotherapist) called the player concerned or parent/guardian within the following three days. The interviewer used a set protocol to determine how the player was progressing, and whether they had sought treatment from a doctor, dentist, or physiotherapist. A phone call was also made the following week to establish whether the player had been able to attend and complete practice and play in that weeks game. Figure 1 gives a copy of the injury incident sheet. To establish the inter-rater reliability of the current data collection methods, two raters observed the same games over a weekend of sport. The $\kappa$ coefficient derived from these data was 0.88 , which is regarded as excellent. ${ }^{13}$ The techniques used to collect these data have also been used by previous researchers, ${ }^{14-16}$ and their validity and reliability have been shown to be adequate. ${ }^{16}$

The areas of interest that were recorded included the time of injury (first to fourth quarter), the consequence of the incidence, the injury mechanism, and the nature and anatomical location of the injury. A minor injury was defined as one where the player was still in discomfort immediately after the game, but was able to play the following week. A moderate injury was defined as one that prevented the player from participating in the following weeks game. When injuries lasted longer, follow up was made each week.
Injury rates per 1000 player exposure hours were calculated using a formula outlined by Norton. ${ }^{17}$ In addition, descriptive statistics and $\chi^{2}$ analysis were used to analyse the data. The $\alpha$ level was set to 0.05 .

\section{Results and discussion}

All 258 games selected for the study were able to be observed. Over a four week period, 5174 players were observed, 1932 boys in rugby union and 1730 in rugby league, and 1512 girls in netball. Different age groups had different numbers of players in each team-for example, for players aged 7-9 the teams in rugby union have only ten players, and above the age of 10 there are 15 players per team. This is why the number of players given does not divide evenly by the number of teams. A total of 4175 player hours were recorded. All players who were injured were followed up to ascertain the extent of their injury. Within the four week data collection period there was no significant change in the playing surface conditions (wet, dry, or frozen) or the ambient air temperature of each game.

INJURY RATES

Table 1 shows that a total of 75 minor and moderate injuries were observed across all sports. This represents an injury rate of 18 per 
Table 1 Number of minor and moderate injuries recorded for each sport

\begin{tabular}{llllll}
\hline & $\begin{array}{l}\text { Number of } \\
\text { players } \\
\text { observed }\end{array}$ & $\begin{array}{l}\text { Number of } \\
\text { minor } \\
\text { injuries } \\
\text { recorded }\end{array}$ & $\begin{array}{l}\text { Number of } \\
\text { moderate } \\
\text { injuries } \\
\text { recorded }\end{array}$ & $\begin{array}{l}\text { Total number } \\
\text { of injuries } \\
\text { recorded }\end{array}$ & $\begin{array}{l}\text { Injuries per } \\
\text { 1000 player } \\
\text { hours }\end{array}$ \\
\hline Rugort & 1932 & 23 & 1 & 24 & 15.5 \\
Rugby league & 1730 & 22 & 14 & 36 & 24.5 \\
Netball & 1512 & 8 & 7 & 15 & 13 \\
Total & 5174 & 53 & 22 & 75 & 18 \\
\hline
\end{tabular}

1000 player hours. With respect to the individual sports, the total injury rate per 1000 player hours for rugby union was 15.5, 24.5 for rugby league, and 13 for netball.

A total of 53 minor injuries were observed across all sports. This represents a minor injury rate of 12.7 per 1000 player hours. With respect to the individual sports codes, a total of 23 minor injuries were recorded in rugby union, eight in netball, and 22 in rugby league. A total of 22 moderate injuries were observed across all sports, 14 from rugby league, seven from netball, and only one from rugby union. This represents a moderate injury rate for all sports of 5.3 per 1000 player hours. With respect to the individual sports, the moderate injury rate per 1000 player hours for rugby league was 9.5, six for netball, and 0.6 for rugby union.

Caution needs to be applied in comparing the results of this study with similar investigations because of the use of differing methodologies, population bases, and injury classification systems. For example, it is difficult to directly compare the results from this study with Watson's ${ }^{4}$ investigation because of incongruous definitions of injury. Watson used physical education teachers to record athletic injuries sustained by their pupils, and found the overall incidence to be 2.94 injuries per 100 children per calendar year. The results from the current study extrapolated to a calendar year amount to 18.8 injuries per 100 children. However, it cannot be concluded that there are significantly more injuries in children's sport when compared with physical education lessons, as Watson's study would have ignored many of the minor injuries that the current study recorded. It would seem important that future studies apply a uniform definition of sports related injury.

The injury rates recorded in this study appear to be considerably lower than those observed by others for adult injury patterns. For example, Norton ${ }^{17}$ (who used an injury definition comparable with our definition of moderate injury) found the adult injury rate for rugby league to be 25 per 1000 player hours. This adult rate is 2.6 times higher than the rate (9.5 per 1000 player hours) found for youths playing rugby league. Dixon ${ }^{18}$ found that the incidence of hospitalising injury for adult rugby union players was $16.6 \%$ of players per calendar year, and Hume ${ }^{10}$ reported that the injury rate for netball players in the Dunedin region was $9.5 \%$. The difference in injury rates between children and adults may be related to the modified rules used for children, the level of force exerted by the children, and/or health related fitness factors such as the level of cardiovascular endurance or degree of flexibility. Further research is required to clarify why adults have a higher injury rate than children. Even though the youth injury rates are relatively low, it is important to note that negative social and physical consequences of children's sports injuries can have an adverse impact on individuals. ${ }^{5}$ Therefore sports administrators and junior coaches should still aim to reduce these injury rates.

Of all observed injuries, $29.4 \%$ required some form of medical treatment. This finding is similar to the $30 \%$ found in the study of Tursz and Crost ${ }^{5}$ for children's sport. Across all sports, 15 individuals required treatment from a doctor and three from a physiotherapist. Of these players, 12 were from rugby league, five from netball, and one from rugby union. No players required dental treatment.

Some researchers ${ }^{19}$ have postulated that fatigue may lead to an increased probability of sustaining an injury. Thus it might be expected that more injuries would occur toward the end of games. However, the results of a $\chi^{2}$ analysis indicated that there was a significant difference $(p<0.05)$ in the distribution of injury over the four quarters, with most occurring in the first three quarters $(24,29$ and $33 \%$ respectively) and only $8 \%$ in the last quarter of the game. It may be that games were being played with less intensity in the last quarter, and hence the injury rate declined. ${ }^{20}$

Figure 2 presents the combined injury rate per 1000 player hours for rugby league and rugby union across age. A similar analysis for netball could not be undertaken because of the unique system of age grouping players in this sport. Although previous research ${ }^{4}$ has noted an increased injury rate as age increases, this study did not confirm this trend. It is not possible to attribute the sudden increase observed at age 14 and then the decrease at age 15 to any particular factor. A more detailed study is required to clarify the relation between physical maturation and injury rates.

INJURY MECHANISM

Sixty one injuries occurred through direct contact with other participants $(n=50)$, the playing surface $(n=6)$, and the ball $(n=5)$. Of these injuries, 45 were minor and 39 were sustained in rugby union and rugby league. With respect to moderate injuries $(n=16)$, thirteen were sustained by direct contact with another

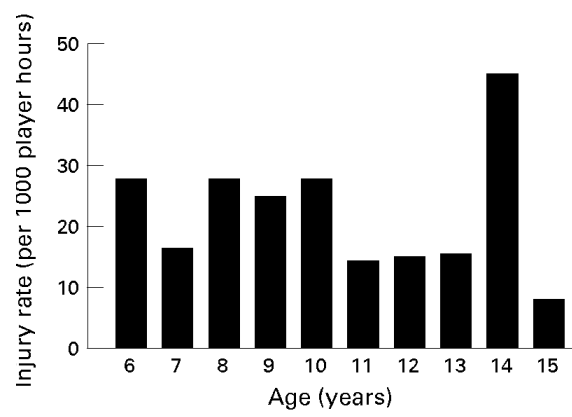

Figure 2 Injury rate per 1000 player hours for rugby union and rugby league combined. 
player, and the remainder were incurred by contact with the surface $(n=2)$ and the ball ( $n$ $=1$ ). Interestingly, 11 of the 16 moderate injuries occurred in rugby league, four in netball and one in rugby union. Fourteen non-contact injuries occurred, six of which were moderate. There was no pattern with respect to the mechanism of injury or sport played.

Dixon $^{18}$ has also noted that a high percentage of injury occurs with contact. He commented that "it is ironic that rugby administrators and lawmakers have substantially changed the laws relating to scrums, line-outs, mauls and rucks, yet have done little to address tackling which is involved in a high percentage of injuries." The large percentage of contact injuries with the opposition-for example, tackles and collisions-indicate that there may still be a need for further rule changes or increased use of protective equipment.

NATURE OF INJURIES

Contusions most often occurred in rugby union and rugby league, and the most common sites of injury were the head, neck, upper thigh, and knee joint. In rugby union the sole moderate injury was a concussion, while in rugby league, three fractures were observed. They were to the patella, clavicle, and distal phalange of the thumb.

In netball, sprains were the most common injury, and these occurred at the fingers, wrist, and ankle joint. The most serious injuries were a fracture of the wrist and a grade three ankle sprain with disturbance to the growth plate.

With regard to whether players had experienced a previous injury to the same site, 16 $(30 \%)$ of the 53 players with a minor injury had sustained a similar injury within the preceding three months. Four $(18 \%)$ of 22 children who had sustained moderate injuries reinjured the same area. The high percentage $(27 \%)$ of children reinjuring the same site may indicate that they are returning to sport before recovery is complete. This is in agreement with Backx et $a l{ }^{6}$ who suggested that incomplete recovery from a previous injury was a factor in $30 \%$ of acute and $50 \%$ of overuse injuries in children's sport. Hume ${ }^{10}$ found similar rates $(33 \%)$ of reinjury with adult netball participants. She concluded that this was an indication of inadequate rehabilitation before resuming netball participation. Results from a major prospective cohort study that focused on rugby union injuries showed that $39 \%$ of the respondents had played against medical advice at some time in their playing history. ${ }^{21}$ Perhaps coaches and players need to be better educated about sports injury rehabilitation and prevention.

CONCLUSIONS

This study has provided estimates of the rates of injury sustained by children in three sports. Results indicate that the incidence of injury in rugby union, netball, and rugby league is low for children aged between 6 and 15 relative to adult rates. These are encouraging findings for they provide further support for the participation of children in such sports.

We thank Jim Borrows for advice during preparation of the study methodology, and the Auckland Institute of Technology for funding. We also thank Dr David Chalmers for valuable advice on the writing of this article.

1 Thomson RW. Youth sport involvement: sociological implications. Coaching New Zealand Annual Conference, 1993, Wellington, New Zealand.

2 Smoll FL, Magill RA, Ash MJ (eds). Children in sport. 3rd ed. Champaign, IL: Human Kinetics, 1988.

3 Lee $M$ (ed). Coaching children in sport. London: E \& FN Spon, 1993.

4 Watson AWS. Sports injuries during one academic year in 6799 Irish school children. Am $\mathcal{F}$ Sports Med 1984;12:6570.

5 Tursz A, Crost, M. Sports-related injuries in children: a study of their characteristics, frequency, and severity, with comparison to other types of accidental injuries. Am $\mathfrak{f}$ Sports Med 1986;14:294-9.

6 Backx FJG, Erich WBM, Kemper ABA, Verbeek ALM. Backx FJG, Erich WBM, Kemper ABA, Verbeek ALM.
Sports injuries in school-aged children: an epidemiological study. Am 7 Sports Med 1989;17:234-40.

7 Backx FJG. Epidemiology of paediatric sports-related injuries. In: Bar-Or $\mathrm{O}$, ed. The child and adolescent athlete. Champaign, IL: Human Kinetics, 1996;163-72.

8 Hillary Commission for Recreation and Sport. Life in New Zealand Survey. Prepared by University of Otago, June 1991.

9 Waller AE, Feehan M, Marshall SW, Chalmers DJ. The New Zealand rugby injury and performance project. I. Design and methodology of a prospective follow-up study. Brf Sports Med 1994;28:223-8.

10 Hume PA. Netball injuries in New Zealand. New Zealand fournal of Sports Medicine 1993;2:27-31.

11 Accident Compensation Corporation. ACC Injury Statistics: Sport. 1989/90 1991;2.

12 Finlay H, Hunter J, Kincs T, O Brien A. Status report of injury in the Auckland region: causes, cost and incidence. Project sponsored by Auckland Area Health Board and The Accident Rehabilitation and Compensation Insurance Corporation, June 1993.

13 Fleiss J. Statistical methods for rates and proportions. New York: John Wiley and Sons, 1981.

4 Garrick J, Requa R. Role of external support in the prevention of ankle sprains. Med Sci Sport 1973;5:200-3.

15 Gutgesell M. Safety of a preadolescent basketball program. American fournal of Diseases of Children 1991;145:1023-5.

16 McKay G, Payne W, Goldie P, et al. A comparison of the injuries sustained by female basketball and netball players. Aust F Sci Med Sport 1996;28:12-17.

17 Norton R. Rugby league injuries and patterns. New Zealand fournal of Sports Medicine 1995;22:37-8.

18 Dixon G. Morbidity of rugby union injuries in New Zealand. New Zealand fournal of Sports Medicine 1993;2: Zealand.

19 Lundin T M, Feuerbach JW, Grabiner MD. Effect of plantar flexor and dorsiflexor fatigue on unilateral postural control Fournal of Applied Biomechanics 1993;9:191-201.

20 Seward HG, Patrick J. A three year survey of Victorian football league injuries. Aust F Sci Med Sport 1992;24:51-4.

21 Gerrard DF, Waller AE, Bird YN. The New Zealand rugby injury and performance project. II. Previous injury experience of a rugby-playing cohort. $\mathrm{Br} \mathcal{F}$ Sports Med 1994;28:229-33. 